\title{
Cervical Cancer Screening Preferences Among Trans-Masculine Individuals: Patient-Collected Human Papillomavirus Vaginal Swabs Versus Provider-Administered Pap Tests
}

\section{Citation}

McDowell, Michal. 2018. Cervical Cancer Screening Preferences Among Trans-Masculine Individuals: Patient-Collected Human Papillomavirus Vaginal Swabs Versus ProviderAdministered Pap Tests. Doctoral dissertation, Harvard Medical School.

\section{Permanent link}

http://nrs.harvard.edu/urn-3:HUL.InstRepos:37006462

\section{Terms of Use}

This article was downloaded from Harvard University's DASH repository, and is made available under the terms and conditions applicable to Other Posted Material, as set forth at http:// nrs.harvard.edu/urn-3:HUL.InstRepos:dash.current.terms-of-use\#LAA

\section{Share Your Story}

The Harvard community has made this article openly available.

Please share how this access benefits you. Submit a story.

\section{Accessibility}


Special thank you to Jenny Potter and Madina Agénor, who have been exceptionally generous with their time throughout this process. 
Note: This paper, accompanying tables, and appendices are largely based on an article published in the August 2017 issue of LGBT Health. The original article can be found here:

McDowell M, Pardee DJ, Peitzmeier S, Reisner SL, Agénor M, Alizaga N, et al. Cervical Cancer Screening Preferences Among Trans-Masculine Individuals: Patient-Collected Human Papillomavirus Vaginal Swabs Versus Provider-Administered Pap Tests. LGBT Health. 2017 Aug;4(4):252-9.

\begin{abstract}
Purpose: Trans-masculine (TM, i.e. persons who have a masculine spectrum gender identity but are assigned female sex at birth) individuals face disparities in cervical cancer screening rates compared to non-transgender women. Some unique barriers to screening in this population are specific to Pap tests. Introduction of self-collected frontal (i.e., vaginal) swabs for human papillomavirus (HPV) testing as a screening strategy may help to alleviate these barriers. This study elucidates cervical cancer screening preferences among TM individuals.
\end{abstract}

Methods: TM individuals participated in in-depth interviews $(n=31)$ and online surveys $(n=32)$ to explore perceptions and experiences regarding cervical cancer screening, including the acceptability of self-collected frontal HPV swabs compared to provider-administered Pap tests. Provider-collected frontal HPV swab acceptability was also explored.

Results: Most TM individuals (92\% in-person and 91\% online participants) preferred either the self- or provider-collected frontal HPV swab to the Pap test. Participants perceived self- and provider-collected frontal HPV swabs to be less invasive, provoke less gender discordance, and promote a greater sense of agency compared to Pap tests. However, some participants expressed concern about HPV swab accuracy and, regarding the self-collected swab, discomfort about the need to engage with genitals they may not want to acknowledge. Individuals who reported positive provider relationships found Pap tests and provider-administered frontal swabs more acceptable than those who did not.

Conclusion: Frontal HPV swabs have the potential to promote regular cervical cancer screening among TM individuals and to narrow screening disparities. Work is ongoing to establish swab accuracy and develop shared decision-making tools. 


\section{Table of Contents}

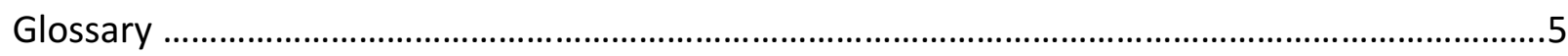

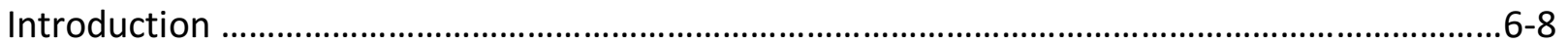

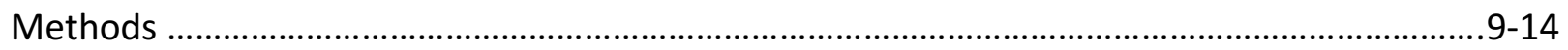

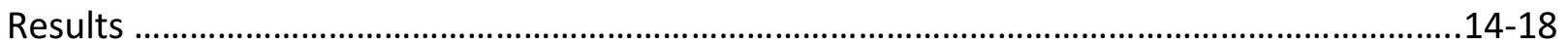

Discussion, Conclusion, Suggestions for Future Work, \& Summary........................................18-22

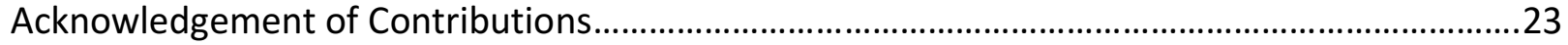

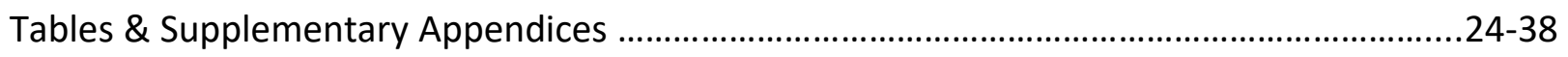

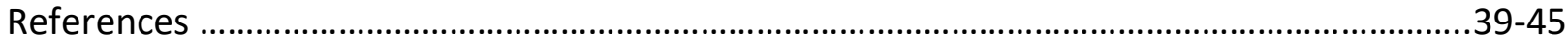




\section{Glossary}

American College of Obstetricians and Gynecologists (ACOG)

Atypical squamous cells of undetermined significance (ASC-US)

Human papillomavirus (HPV)

Sexually transmitted infection (STI)

Trans-masculine (TM) 


\section{Introduction}

Cervical cancer, which is caused by the sexually transmitted infection (STI) human papillomavirus (HPV), is associated with significant morbidity and mortality in individuals with a cervix (1-4). HPV is a virus passed through direct genital contact and is the most common STI in the United States $(3,5)$. Certain types of HPV are considered high-risk, as they cause cancer in different areas of the body, including the cervix (6). A recently estimated prevalence in nontransgender women in the United States for high-risk genital HPV was 20.4\% (6).

Trans-masculine (TM) individuals have a masculine spectrum gender identity (men, male, trans man, trans male, non-binary, or another diverse gender identity on the masculine continuum) and are assigned female sex at birth (7). About 1.4 million adults in the United States identify as transgender (8); no data regarding the population make up of TM individuals in the United States exist to date. The majority of TM individuals do not undergo gender affirming genital surgery, and therefore retain natal reproductive organs (9). Thus, TM individuals are susceptible to cancers of the genital tract, including cervical cancer (10). Recent research shows that TM individuals are at no lower risk for STIs and for cervical abnormalities as compared to non-transgender women $(3,11)$.

The American College of Obstetricians and Gynecologists (ACOG) recommends that TM individuals with cervices follow the same screening guidelines as non-transgender women $(12,13)$. In the United States, experts recommend screening be initiated no earlier than age 21 in immunocompetent, asymptomatic people and discontinued in people aged 65 and older with no increased risk factors, history of high-grade dysplasia, or recent screening gaps (14-16). Approved cervical cancer screening methods include the Papanicolaou (Pap) test, as well as HPV testing.

The cervical Pap test samples cells from the cervix, and can identify abnormal cells in the transformation zone and the junction of the ecto- and endocervix (17). To obtain cells, either a spatula and endocervical brush or a broom can be used. With the former method, a spatula is used to obtain cells from the ectocervix, and subsequently an endocervical brush is inserted into the os to collect endocervical cells; alternatively, a broom can be used to simultaneously 
collect ecto- and endocervical samples (17). A Pap test specimen thus permits examination of cells (i.e., cytology), but not of tissue structure (i.e., histology) (18).

HPV testing is used to detect the virus itself, as opposed to cell changes. Four HPV tests are approved by the United States Food and Drug Administration (18). Three of the tests provide pooled results, whereas the cobas HPV test specifically identifies two HPV strains (types 16 and 18) and pools results for 12 other types (18). HPV testing may be used as part of primary screening for cervical cancer or for reflex (follow-up) testing after Pap cytology reveals atypical squamous cells of undetermined significance (ASC-US) (19).

For people under 30 years of age, Pap testing alone is recommended at three-year intervals (20). For those 30 years or older, Pap test screening may continue every three years, or the screening interval may be extended to every five years if Pap/HPV co-testing is performed, provided both tests are initially negative (14-16). The cobas HPV test alone is approved for primary cervical cancer screening in people $\geq 25$ years of age $(17,21)$. In fact, one recent study found that cobas HPV DNA testing had superior sensitivity compared to screening utilizing cytology (22).

TM adults are less likely to be up to date on cervical cancer screening as compared to non-transgender women $(11,23,24)$. HPV vaccination rates in this population are unknown. TM adults are at a ten-fold increased odds of having an inadequate Pap test compared to nontransgender females (11). Longitudinal testosterone therapy for gender affirmation may induce vaginal atrophy and decrease vaginal lubrication, which may make specimen collection more challenging $(25,26)$. Some evidence suggests a positive association between the length of time on testosterone therapy and increasing rates of inadequate Pap specimens (11). Gender identity disparities in cervical cancer screening may be due to a number of factors that increase the physical and emotional discomfort associated with Pap tests, as well as structural barriers to obtaining health care (27). Such factors may include a disconnect between biological sex and self-identified gender; desire to ignore the existence of natal reproductive structures; lack of knowledge that the cervix remains post supra-cervical hysterectomy; high frequency of trauma and consequent posttraumatic distress; heightened anxiety about having genitalia examined; fear of discrimination in the medical setting; vaginal atrophy from long-term testosterone 
therapy, making passage of the speculum more painful; providers refusing to provide care or not knowing the guidelines appropriate for TM patients; and insurance companies blocking coverage of cervical Pap tests for patients with male gender markers $(9,23,24,26-29)$.

A cervical cancer screening method that is accurate and responsive to the unique needs of TM individuals is critical. Current screening methods require an office visit and include speculum examination, either or both of which are unacceptable to some patients. This exam could potentially be avoided by self-collection of specimens for HPV testing. Past studies exploring specimen self-collection in hard-to-reach, non-transgender, female patients included patient collection of vaginal samples using a tampon, Dacron or cotton swab, cytobrush, or cervico-vaginal lavage $(30,31)$. Self-sampling is highly acceptable to non-transgender women (32-37), as it facilitates access to screening for this population in low-resource areas (38-42). In addition, self-sampling has been shown to improve screening in under-screened women as compared to recall cytology letters (43-45). Because under-screening is a risk factor for cervical cancer, primary HPV self-sampling represents an important potential screening option for the TM population. No published studies to date have explored the acceptability and clinical performance of self-sampling among TM individuals (3).

The aims of this study were to 1 ) assess TM individuals' experiences with cervical cancer screening to identify reasons for preference for frontal (i.e., vaginal) HPV swabs compared to Pap testing and 2) explore the acceptability of self- versus provider-administered frontal HPV swabs - options that do not require a speculum exam, but, in the case of the self-swab, require an individual to interact with genitals that might trigger gender discordance. ${ }^{*}$ This study addresses critical gaps in current knowledge regarding cervical cancer screening method acceptability and preferences among TM individuals. We hypothesized that, given the acceptability of alternate screening strategies amongst hard-to-reach non-transgender women, primary self-collected HPV screening may also be acceptable in this population. Our hope is that such an option could alleviate screening disparities for this underserved and often overlooked patient population.

\footnotetext{
*We use "gender discordance" to mean any negative psychological feeling in which a stimulus (such as a body part, pronoun, social interaction) does not align with the individual's gender identity.
} 


\section{Methods}

In 2013, participants completed either an in-person, semi-structured in-depth interview $(n=31)$ or an online survey $(n=32)$; no individual completed both. This mixed-methods study employed a modified grounded theory approach with thematic analysis for the qualitative portion and descriptive statistics for quantitative data. The in-depth interviews were conducted at Fenway Health, a Federally Qualified Health Center and research facility specializing in primary care for sexual and gender minority people in Boston, Massachusetts $(46,47)$. Grounded theory is a rigorous research method where conceptual frameworks or theories are constructed through building inductive, or bottom up, theoretical analyses from data and then checking theoretical interpretations from the data (47). Thematic analysis is a flexible qualitative research method which allows the identification, analysis, and reporting of themes from data (48). Data from interviews and surveys were triangulated to understand TM individuals' cervical cancer screening preferences (49). The Fenway Health Institutional Review Board approved the study procedures.

\section{In-depth interviews}

Before initiation of interviews, a semi-structured interview guide was reviewed by experts in qualitative research, transgender health, and cervical cancer. The guide addressed healthcare utilization and interactions with health care providers, access to health information, perceptions, knowledge, and beliefs regarding HPV, as well as cervical cancer risk and prevention, previous Pap test experiences, gender identity in the context of cervical cancer screening, and attitudes regarding HPV swabs (Supplementary Appendix A). Individuals were recruited through purposive sampling techniques including tabling at community events, flyers, and social media (50-52). Purposive sampling involves the selection of information-rich cases for in-depth study (52). From June to July 2013, in person, in-depth interviews were conducted in a private room at Fenway Health with 31 TM individuals. Written informed consent was obtained from participants. Data collection ended due to achievement of thematic saturation (47). Thematic saturation was predicted based on sample size recommendations for grounded theory studies offered by Morse and Creswell $(53,54)$. In line with these guidelines, we 
conducted 31 in-depth interviews, in which we reached thematic saturation, as the team determined that no new substantive information would be acquired with additional sampling (55).

The interviewer, a non-transgender woman, had experience working with transgender populations and checked in regularly with transgender team members for guidance. Participants were eligible to participate if they identified on the TM spectrum and were assigned female sex at birth, were 21-64 years-old (aligned with cervical cancer screening guidelines described above), had a cervix, and could travel to Fenway Health in Boston $(13,19,56)$. Interviews were conducted in English and lasted 60-125 minutes (average length of interview time was 93 minutes).

Participants were also asked to rank cervical cancer screening methods, including selfand provider-collected frontal HPV swabs and provider-administered Pap tests, based on their preferences. The interviewer asked participants about preferred anatomical terminology before explaining the screening methods, which included display of the speculum, cytobrush, cervical spatula, and HPV swabs. Participants then ranked screening preferences. Following the interview, participants completed a brief sociodemographic questionnaire and received US\$50 for their participation in the study.

Interviews were audio recorded, transcribed verbatim, entered into ATLAS.ti (2015, version 7), and discussed amongst team members. Data analysis was guided by the principles of grounded theory, as well as thematic analysis $(47,48,54,57)$. We used a coding approach guided by grounded theory for two reasons. First, grounded theory coding generates rich, nuanced data analysis due to the inductive, or bottom-up, approach the grounded theory coding facilitates (47). Second, grounded theory coding shifts weight to the participant words and perspectives, as the coding process and analysis rely on data from the field (54). A full grounded theory coding approach was not employed, as theoretical sampling, or further data collection after theory generation, did not occur.

After initial data coding, we shifted to thematic analysis to use the generated codes to identify data categories and develop themes. We made this shift to honor the study goals. As two aims of the study were to assess TM individuals' experiences with cervical cancer screening 
and explore screening preferences, we used thematic analysis to inform best practices based on participant perceptions (48). We concluded that identification of participant-generated themes through thematic analysis would better facilitate honoring these aims as opposed to theory generation through a grounded theory approach.

Authors involved in the data analysis, "coders," began the grounded theory-informed coding process by reading all of the transcripts, and then each coding a different transcript using a line-by-line approach. This process facilitated active engagement with the data and inspired coders to begin thinking about the theoretical ideas they suggested (47). After this initial stage, the coders discussed their analysis strategies on the initial transcripts, resolved discrepancies, and, with critical input from broader team, developed a provisional codebook. The next phase included adoption of a focused coding approach, with each coder reviewing an additional transcript using the provisional list of inductive codes that emerged from the original review of data. Focused coding involved concentration on the codes that arose most frequently or appeared most significant among the initial codes, and testing of these codes against larger batches of the data (47). Under the close supervision of two auditing team members, the coders ultimately discarded, combined, and created new codes to develop a final codebook, which was used to code the remaining participant transcripts according to the focused coding approach (47). The coders next applied axial coding to the data by delineating relationships and specifying dimensions of code categories. Through axial coding, coders brought the data back together after the initial fracturing of the line-by-line process (47). For the next stages of data inquiry, the coders transitioned to thematic analysis. Coders formulated common themes through analysis of the categories generated through axial coding (48). The themes that emerged from the data relating to participant preferences surrounding cervical cancer screening are presented in this thesis.

\section{Online survey}

After completion of patient interviews, an online survey was administered to capture perspectives of individuals who potentially did not feel comfortable discussing cervical cancer screening in-person, and thus whose care experiences may have differed from participants 
presented to the health center. Online survey participants were eligible to participate if they identified on the TM spectrum and were 21-64 years-old. There were no restrictions regarding participant geography or cervix retention. An informed consent waiver was obtained for all survey participants. Individuals were recruited through national organizations and by word-ofmouth. No direct interaction between study staff and survey participants occurred; no incentive was provided. The survey was open from August 15 through September 30, 2013.

Closed- and open-ended questions were included to gather information on Pap test utilization, barriers and facilitators to cervical cancer screening, and screening method preferences (Supplementary Appendix B). The survey was adapted from the in-person interview guide. The survey was completed by 63 participants via LimeSurvey, an IRB-compliant survey tool. Participants could skip any question. Of the 63 participants, 32 completed all questions pertaining to screening preferences; these 32 were included in the quantitative analyses (Tables 1 and 2).

Following analysis of the in-person interview data, open-ended question responses from the online survey respondents were read for additional and disconfirming themes $(47,58)$. Analysis proceeded as above. Although the online surveys included a qualitative component, the in-depth interviews allowed for collection of richer qualitative data, as rapport-building and question probing were feasible. No additional or disconfirming themes emerged. Quotes used in the results section are thus from the in-depth interviews. Quantitative results from in-person interviews and online surveys are presented separately rather than pooled, as differences in eligibility criteria and how screening modalities were explained may make results noncollapsible.

\section{Establishment of Qualitative Data Trustworthiness}

Considerations were taken to establish trustworthiness in the qualitative portions of the data, building off of the evaluative criteria first proposed by Lincoln and Guba (58). In their seminal text, the authors propose credibility, transferability, dependability, and confirmability as the four pillars requisite to establishing trustworthiness in qualitative research (58). Credibility establishes confidence in the truth of the findings. Transferability speaks to the 
applicability of the findings to other contexts. Dependability underlies whether the findings would be repeated if the inquiry were replicated. Finally, confirmability establishes the degree to which findings are established by the data, as opposed to the biases and motivations of the researchers (58).

First, to establish data credibility, the coders utilized prolonged engagement, triangulation, peer debriefing, and negative case analysis (58). With regard to prolonged engagement, coders invested sufficient time to fully immerse themselves in published data regarding TM health disparities and care delivery access. In addition, coders discussed transference and distortions introduced by coder biases and unfamiliarity with the target population. An awareness of positional reflexivity, or researcher awareness of how personal experiences influence data interaction, was discussed frequently amongst coders during engagement with and analysis of data (58). Coders also employed multiple modes of triangulation to establish credibility, including use of different sources, methods, and investigators. Specifically, sixty-three different sources were sampled, including both the interview and online survey participants; both qualitative and quantitative, as well as survey and interview methodologies were utilized; and three different coders analyzed the data. The three coders also engaged in peer debriefing with the five additional team members. Although these five members were interested parties, they were not as immersed in the data as the three coders were, and thus were able to challenge the coders to approach the data in novel ways. The peer team members assisted by probing coder biases, questioning code meanings, and clarifying the basis of code interpretations. The coders were able to test hypotheses through peer debriefing as well (58). Finally, the coders used negative case analysis to establish credibility. This process involved reviewing participant transcripts for data that disconfirmed themes identified by coders (58).

Second, although transferability in qualitative research is not as readily established as external validity may be in quantitative data, we aim to provide a database here that makes future transferability judgments possible. We document the time and context in which these results and our analyses were found to hold, such that potential appliers may make transferring judgments where enough similarities exist (58). 
Third, in an effort to address the dependability of our analysis, we attempted to use modified stepwise replication. Stepwise replication involves researchers separately conducting inquiry with the hopes of yielding the same result to establish method, and thus finding, dependability. To accomplish this, the three coders initially dealt with the data sources separately, and, in effect, conducted their inquiries independently with the initial line-by-line coding. Although the initial analysis was done independently, the coders communicated frequently about divergences, as grounded theory by virtue is emergent, and therefore does not lend itself well to stepwise replication (58).

Finally, to reconfirm dependability and establish confirmability, we audited our inquiry. Two team members who were experts in both qualitative analysis, as well as transgender health, and who were not coders, closely reviewed the coder analyses, both to attest to the dependability of the method, as well as the to confirm both the dependability, as well as the confirmability of the interpretations (58). This audit included review of the original interviewing recordings as well as transcribed reports transcripts, the initial and subsequent codebooks, and process notes, coder memos and discussions regarding codes, categories, and themes. The auditors determined that the findings were indeed grounded in the data, as audit trail linkages were established using the generated codes. The auditors also queried for coder biases that created distortions of the data interpretations.

Through these metrics, we attempted to ensure the trustworthiness of our findings through pursuit of honest, generalizable, consistent, and neutral data collection and analysis.

\section{Results}

Quantitative Findings

Sociodemographic characteristics of interview $(n=31)$ and online survey $(n=32)$ participants are presented in Table 1. Preferences for screening methodologies are presented in Table 2. The majority of participants (94\% interview, 91\% online) preferred the self- and provider-administered HPV swab to the Pap test. When comparing self- versus providercollected frontal HPV swabs, most participants (71\% interview, 53\% online) preferred the selfto the provider-swab. 


\section{Qualitative Findings}

\section{Preference for frontal HPV swab}

Most participants preferred either swab type to the Pap test because swabs were perceived to: 1) be less emotionally invasive, 2) provoke less gender discordance as compared to Pap testing, 3) be less physically uncomfortable, and 4) promote a greater sense of agency (with the self-swab).

Participants cited emotional discomfort with the Pap test as a chief reason for preferring either swab. Participants described Pap tests as "invasive." One participant explained:

[The provider-administered HPV swab] would less feel like I'm being inspected and like less vulnerable, you know. I mean obviously you are still like naked, but it's like, less like 'we're really looking at you' and more just like, 'oh we just need to get a sample...'

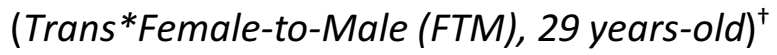

One participant stated that their screening behavior might change if the vulnerability associated with the Pap test were no longer present:

[I]f I could do [the self-administered HPV swab] myself I'd be more inclined to do that on a regular regime ... Simply 'cause it means I'm not as vulnerable. (Trans male/genderqueer, 50 years-old)

Several participants stated that the Pap test was less desirable than either swab type because the Pap test led to gender discordance:

I identify myself as a man and I think to have something physically bulky shoved up me [with the Pap test]....that's more traumatic opposed to a [provider-administered] swab where....you blink and it's over. (Male/FTM, 21-years old)

\footnotetext{
† The gender identities listed parenthetically after quotes are the identities indicated by the participants during the in-person interviews.
} 
Several participants cited physical discomfort with speculum insertion, cervical sampling, and other sensory triggers (e.g., speculum "clicking," cytobrush wire) as negative aspects of the Pap test, influencing their preference for swabs. The speculum was the most objectionable part of the Pap test for many participants:

...in general the speculum looks really barbaric.....with the speculum it's waiting, getting a speculum in, opening it, grabbing the brush, doing that whole thing. (Genderqueer, 31 years-old)

Participants also reported that the Pap test procedure itself was a source of physical discomfort:

...even with that little brush thingy, you can FEEL that, I don't recall doctors telling you that but you can definitely feel them using that tool. So yeah, definitely the HPV tool [swab] seems a lot more safer I guess in terms of the person's um, mental state... (Trans male/Genderqueer, 50 years-old)

Many participants cited maintenance of agency and control as contributing factors in their preference for the self-swab:

The agency, you know, the feeling that I am in control here, and that nobody who I don't want touching my body is going to touch my body. (Male with complicated bits, 34 years-old)

One participant cited a preference for the self-swab, or having his partner administer the swab at home, to avoid re-traumatization:

...if I could take the supplies home myself and do it then....I trust my partner and I could have him go and do the little swab thing and it would just be less emotional because I have that emotional bond with my partner....the DV [domestic violence] emotions and stuff like that are less likely to surface if it's me and my partner opposed to somebody else that I'm not physically connected with. (Trans guy, 28 years-old) 


\section{Concerns with the frontal HPV swab}

Some participants expressed concerns about: 1) the accuracy of self-swabs, 2) the desire for a provider-conducted visual exam, and 3) discomfort about the need to engage with genitals during the self-collection process.

Several participants were concerned about the accuracy of either swab compared to a Pap test, or that the self-swab might be less accurate due to user error. One participant explained:

I would rank, just do it the old-fashioned way [i.e. Pap], have the doctor do the swab, and then do it yourself because...if you have to repeat that test, it sucks. So why put the doctor and the patient in the situation where they have to repeat what they've just done because they got inconclusive results. I don't know how sensitive that swab thing is, and I don't know what the lab is going to do if they don't get enough material, so I wouldn't go with it. (Trans masculine, 23 years-old)

A few participants stated they would prefer the Pap test to either swab due to desire for a more thorough exam, including a visual exam of the cervix:

And actually, to be honest with you because well, I'm older, I like to know that my cervix looks okay. But actually I would prefer to see, know that the doctor - my doctor, that I trust, has looked and seen my cervix and know that it's okay. (Trans, 53 years-old)

When asked to choose between the self- and provider-swabs, several participants noted that the self-swab would force them to engage with body parts they would prefer not to acknowledge. One participant explained that with a provider-swab,

You can switch off if someone else does...it's kind of like, dissociating from yourself....it's kind of though you can disembody from your own body for a second, whereas if you physically have to do it, then you're acknowledging yourself... (Male, 34 years-old)

A few participants cited lack of familiarity with their anatomy as a reason they would prefer not to perform the self-swab: 
...probably better with someone who can aim and I mean there have been several times when I've been curious, like would it hurt if I put my finger in so I tried but I couldn't find it. Probably because I was clenching. But, still, I can't find it. So, I don't wanna. (Trans*FTM, 51 years-old)

\section{Patient-provider relationships and cervical cancer screening preferences}

Preferences for screening methodologies varied with the quality of the relationship between the participant and their provider. While some preferred the self-swab because it "takes away all of the provider awkwardness" (Trans man, 49 years-old), several other participants cited willingness to have a provider-swab if they knew and liked their provider:

If I had a relationship with the provider, then I would much rather them do it so they get it right. If you don't know [what provider] you're going to get, I would do it myself. (Queer/Trans masculine, 29 years-old)

\section{Discussion}

Over $90 \%$ of TM individuals in both groups expressed a preference for either self- or provider-collected swabs for cervical cancer screening as compared Pap tests, suggesting these modalities could reduce screening disparities (11). Many participants stated that frontal sample self-collection would result in less physical and emotional discomfort, improved agency, and reduced gender dysphoria, addressing several barriers to cervical cancer screening adherence for TM individuals $(11,59,60)$.

\section{Between group differences}

Preferences for screening modalities were qualitatively similar across in-person and online respondents, but in-person participants more strongly preferred the self-swab (71\% of in-person respondents ranked the self-swab as their preferred option, versus $50 \%$ of online respondents). The ordering that placed the provider-swab first and the self-swab last was more popular among online participants ( $22 \%$ online; $3 \%$ in-person). Approximately one-third of 
online respondents would not choose a self-swab over a Pap test, whereas $90 \%$ of the inperson respondents would do so. These findings highlight the importance of method choice.

The online survey was developed due to feedback from in-person interview participants who stated that they had peers with significant gender discordance around Pap tests and would find in-person interviews too psychologically discomfiting, but who would appreciate sharing screening preferences online. The lower appeal of self-swabs in the online group may reflect greater gender discordance, and thus a decreased desire to engage with genitals during the self-collection process, as compared to the in-person cohort.

Increasing uptake of health interventions often hinges on the provision of a variety of options that address adherence barriers in different segments of the population. Our results suggest that offering the self-swab, provider-swab, and Pap test as screening options could optimize cervical cancer screening coverage in the TM community.

\section{Comparison with non-transgender women}

Our findings are consistent with studies in non-transgender women that demonstrate preference for self- versus provider-administered cervical cancer screening methods $(61,62)$. Several barriers to implementation of self-swabs cited by TM participants overlap with those reported by non-transgender women, particularly surrounding concerns with technical administration of self-collection $(62,63)$. This barrier could be addressed with patient education.

Unique concerns expressed by TM individuals in this study include gender discordance during the Pap test, significant physical discomfort associated with sample collection (perhaps enhanced due to testosterone-induced epithelial atrophy) $(59,64)$, emotional discomfort associated with the invasiveness of the Pap test, gender dysphoria in acknowledging genitals while self-collecting a frontal specimen, and issues surrounding agency and control. The option of having a trusted provider, friend, or partner assist in performing a frontal HPV swab may be helpful for TM individuals. 
Swab accuracy and visual exam concerns

Several participants voiced concerns with the accuracy of the swab as compared to Pap tests. To address concerns surrounding swab accuracy, researchers are currently undertaking a mixed-methods bio-behavioral study to assess the clinical performance and acceptability of frontal self-collected swabs for HPV DNA testing compared to provider-collected cervical swabs and cervical cytology in a sample of $150 \mathrm{TM}$ individuals. If the patient- and provider-collected swab test performance in TM individuals have sensitivity and specificity comparable to Pap tests, these sampling modalities could provide important new screening options for TM individuals who have previously avoided or declined screening (65). These findings have important implications for improving the delivery of preventive sexual health to this vulnerable patient population.

Some participants cited concern about the lack of a visual exam of the cervix if opting for a self- or provider-collected frontal HPV swab test without speculum insertion. Visual inspection of the cervix after application of acetic acid or Lugol's iodine has been found to be an effective screening methodology in low-resource settings where cytology and HPV testing are not widely available (66). The incremental value of simple visual inspection of the genitals during speculum exam performed for the purpose of cervical cancer screening via cytology and/or HPV in resourced settings has not been demonstrated convincingly, however (67).

\section{Patient-provider relationship}

Importantly, this study highlights the enormous impact of the patient-provider relationship on cervical cancer screening decision-making among TM individuals. TM individuals with a strong therapeutic alliance with their providers were more willing to undergo screening, including Pap testing, than those who did not have a positive provider relationship. Therefore, building patient provider trust by initially offering reluctant patients the option of swab testing could provide a gateway to performance of needed downstream testing -i.e., reflex cytology or colposcopy-after positive primary HPV screening results $(27,68,69)$. 


\section{Limitations}

This study has several limitations. First, we assessed perceived acceptability of cervical cancer screening techniques; participants did not undergo any actual screening procedures (27). In addition, participants were not queried about willingness to undergo downstream procedures, such as reflex cytology or colposcopy, in the event of a positive screening result. Second, studies that include a greater number of TM individuals of color and from lower socioeconomic backgrounds are needed to assess and improve generalizability of the findings. Third, $61 \%$ of participants reported having had a Pap test in the last 12 months, representing considerably higher Pap testing frequency than recorded in previous studies of TM individuals (59). Fourth, certain demographic questions (see Table 1) were not collected from the online survey participants due to concern for excessive participant burden, which limited analysis of these data. Last, further steps could have been taken to better ensure trustworthiness of the qualitative data analysis. For example, to better establish credibility, future research in this area can engage in peer debriefing with disinterested parties and complete member checking with TM participants (58).

\section{Conclusion}

This study represents an important step in understanding the potential of primary cervical cancer screening using self- or provider-collected frontal HPV swabs to reduce screening barriers among TM individuals. In the meantime, providers must strive to a) establish trusting relationships with TM patients, b) acknowledge that cervical cancer screening procedures may elicit physical and emotional discomfort, and c) ask TM patients how to make screening more comfortable.

\section{Suggestions for Future Work}

Additional qualitative and quantitative research that incorporates more diverse samples of TM individuals, involves actual clinical comparisons, and explores test performance are needed to inform clinic- and community-based interventions to reduce screening disparities. Maximum variation purposive sampling, in which individuals from different regions of the 
country, with different racial, ethnic, and socioeconomic backgrounds are sampled, would be helpful in capturing a greater heterogeneity of experiences (55).

\section{Summary}

TM individuals face significant disparities in cervical cancer screening rates. Introduction of self-collected frontal swabs for HPV DNA testing as a primary screening tool may address some of the barriers specific to the TM population. This study elucidated cervical cancer screening preferences among TM individuals through participant engagement in in-depth interviews and online surveys. Most TM individuals preferred either the self- or providercollected frontal HPV swab to the Pap test. Participants perceived frontal HPV swabs to be less invasive, provoke less gender discordance, and promote a greater sense of agency compared to Pap tests. Some participants cited concern regarding HPV swab accuracy and, regarding the self-collected swab, discomfort about the need to engage with genitals they may not want to acknowledge. Individuals who reported positive provider relationships found Pap tests and provider-administered frontal swabs more acceptable than those who did not. Frontal HPV swabs may improve cervical cancer screening adherence among TM individuals. 


\section{Acknowledgement of Contributions}

I began work on the TRANSprev project during my first year of medical school (Fall 2013) after discussing the project with Ida Bernstein and Jennifer Potter. I spent my first year of medical school learning about grounded theory, and read Kathy Charmaz's book on the topic. Ida Bernstein and I also met with Madina Agénor to solidify my understanding of this technique. At the end of my first year through my M1 summer, Ida Bernstein, Natalie Alizaga and I transcribed verbatim the audio recordings of the in-person, in-depth participant interviews conducted by Sara Peitzmeier. Next, Ida Bernstein, Natalie Alizaga, and I conducted qualitative analysis of the interviews, using first a line-by-line and then a focused coding approach. We used a codebook comprised of inductive codes, created with the assistance of Madina Agénor and Sarah Peitzmeier. The three of us met several times to discuss our coding decisions, reconcile discrepancies, and revise the codebook. Along with the other members of our team, we developed categories based on multiple codes using axial coding and formulated themes comprised of multiple categories, which was facilitated by our writing memos. We then abstracted these themes into what would later become frameworks for paper topics. Ida Bernstein, Natalie Alizaga, and I completed this process during my second year of medical school (2014-2015).

During my third year of medical school into my MPH year (2015-2017), Dana Pardee and I took the lead on the paper on factors that influence cervical cancer screening preferences amongst participants. We began the paper drafting process in October 2015 and met monthly with each other, and every couple of months with the larger group, to discuss the progress of the paper. With the incredible help of my team members, I submitted the paper at the beginning of my MPH year and it was accepted for publication in LGBT Health in January 2017. With the invaluable contributions of rest of the team, I spearheaded the iterative revision processes and the paper was ultimately published in the August 2017 journal issue. 
Tables \& Supplements

Table 1. Sociodemographic characteristics of in-depth interview $(n=31)$ and online survey ( $n=32)$ participants.

\begin{tabular}{|c|c|c|c|c|}
\hline & \multicolumn{2}{|c|}{$\begin{array}{l}\text { In-depth Interview } \\
\text { Participants }(n=31)^{a}\end{array}$} & \multicolumn{2}{|c|}{ Survey Participants $(n=32)^{b}$} \\
\hline & $\mathrm{n}$ & $\%$ & $\mathrm{n}$ & $\%$ \\
\hline \multicolumn{5}{|l|}{ Gender Identity } \\
\hline Male & 7 & 22.6 & 17 & 53.1 \\
\hline $\begin{array}{l}\text { FTM } / \text { Transgender/Trans } \\
\text { man/Trans masculine }\end{array}$ & 4 & 12.9 & 28 & 87.5 \\
\hline Transsexual & 0 & 0 & 7 & 21.9 \\
\hline Genderqueer & 1 & 3.2 & 8 & 25.0 \\
\hline Two-spirit & 0 & 0 & 1 & 3.1 \\
\hline 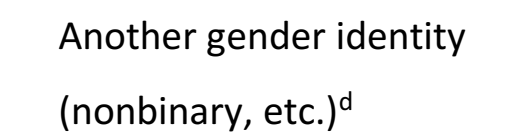 & 19 & 61.3 & 2 & 6.2 \\
\hline \multicolumn{5}{|l|}{ Age } \\
\hline Mean age in years (SD; range) & \multicolumn{2}{|c|}{$33.1(10.7 ; 21-56)$} & \multicolumn{2}{|c|}{$31.7(7.9 ; 23-58)$} \\
\hline $21-29$ years & 16 & 51.6 & 12 & 37.5 \\
\hline $30-39$ years & 8 & 25.8 & 17 & 53.1 \\
\hline $40-49$ years & 2 & 6.5 & 1 & 3.1 \\
\hline $50-59$ years & 5 & 16.1 & 2 & 6.2 \\
\hline
\end{tabular}




\begin{tabular}{|c|c|c|c|c|}
\hline Race/ethnicity ${ }^{b}$ & & & & \\
\hline White & 24 & 77.4 & 30 & 93.8 \\
\hline $\begin{array}{l}\text { Black/African } \\
\text { American/Caribbean }\end{array}$ & 3 & 9.7 & 1 & 3.1 \\
\hline Hispanic/Latino & 1 & 3.2 & 2 & 6.3 \\
\hline Multiracial & 3 & 9.7 & 3 & 9.4 \\
\hline \multicolumn{5}{|l|}{$\begin{array}{l}\text { Gender of Sexual Partners in } \\
\text { Last } 12 \text { Months }{ }^{b}\end{array}$} \\
\hline Cisgender women & 16 & 51.6 & 19 & 61.3 \\
\hline Transgender women & 2 & 6.5 & 3 & 9.7 \\
\hline Cisgender men & 7 & 22.6 & 13 & 41.9 \\
\hline Transgender men & 7 & 22.6 & 5 & 16.1 \\
\hline $\begin{array}{l}\text { Other (non-binary; } \\
\text { genderqueer woman) }\end{array}$ & 2 & 6.5 & 0 & 0 \\
\hline \multicolumn{5}{|l|}{ Educational attainment ${ }^{\mathrm{e}}$} \\
\hline Less than high school & 0 & 0 & - & - \\
\hline $\begin{array}{l}\text { High school diploma or } \\
\text { GED }^{3}\end{array}$ & 1 & 3.2 & - & - \\
\hline Some college & 7 & 22.6 & - & - \\
\hline
\end{tabular}

${ }^{3}$ General Education Development 


\begin{tabular}{|c|c|c|c|c|}
\hline College degree & 10 & 32.3 & - & - \\
\hline $\begin{array}{l}\text { Some graduate work (no } \\
\text { degree to date) }\end{array}$ & 5 & 16.1 & - & - \\
\hline Graduate/Professional & 8 & 25.8 & - & - \\
\hline \multicolumn{5}{|l|}{ Annual individual income $(\$)^{\mathrm{e}}$} \\
\hline Less than 5,000 & 4 & 12.9 & - & - \\
\hline 5,000 to 9,999 & 5 & 16.1 & - & - \\
\hline 10,000 to 19,999 & 5 & 16.1 & - & - \\
\hline 20,000 to 29,999 & 5 & 16.1 & - & - \\
\hline 30,000 to 39,999 & 2 & 6.5 & - & - \\
\hline 40,000 to 49,999 & 2 & 6.5 & - & - \\
\hline 50,000 or more & 7 & 22.6 & - & - \\
\hline Refuse to answer & 1 & 3.2 & - & - \\
\hline \multicolumn{5}{|l|}{ Has health insurance ${ }^{e}$} \\
\hline Yes & 28 & 90.3 & - & - \\
\hline No & 3 & 9.7 & - & - \\
\hline \multicolumn{5}{|l|}{$\begin{array}{l}\text { Time since last visit with a } \\
\text { healthcare provider }\end{array}$} \\
\hline 6 months or less & 27 & 87.1 & - & - \\
\hline 6 months - 1 year & 4 & 12.9 & - & - \\
\hline
\end{tabular}




\begin{tabular}{|l|c|c|c|c|}
\hline 1-3 years & 0 & 0 & - & - \\
\hline 3+ years & 0 & 0 & - & - \\
\hline Pap test in last 12 months & & & & \\
\hline Yes & 19 & 61.3 & - & - \\
\hline No & 12 & 38.7 & - & - \\
\hline
\end{tabular}

${ }^{a}$ Interview participants were offered a write-in answer choice for gender identity. Survey participants had the option of selecting one or multiple answer choices, or writing in their answer.

${ }^{\mathrm{b}}$ Multiple selections allowed; will not equal $100 \%$.

c Female-to-male.

${ }^{d}$ Write-in self-descriptions by participants.

eThese data were only collected from in-person interview participants. 
Table 2. Preference data from in-person and online survey participants.

\begin{tabular}{|c|c|c|c|c|}
\hline & \multicolumn{2}{|c|}{$\begin{array}{l}\text { In-depth Interview } \\
\text { Participants }(n=31)\end{array}$} & \multicolumn{2}{|c|}{ Survey Participants $(n=32)$} \\
\hline & $\mathrm{n}$ & $\%$ & $\mathrm{~N}$ & $\%$ \\
\hline $\begin{array}{l}\text { Ranking in order of } \\
\text { decreasing preference } \\
\text { provided by participants }\end{array}$ & & & & \\
\hline $\begin{array}{l}\text { Self-swab > Provider-swab }> \\
\text { Pap test }\end{array}$ & 22 & 71.0 & 16 & 50.0 \\
\hline $\begin{array}{l}\text { Self-swab > Pap test > } \\
\text { Provider-swab }\end{array}$ & 0 & 0 & 0 & 0 \\
\hline $\begin{array}{l}\text { Provider-swab > Self-swab > } \\
\text { Pap test }\end{array}$ & 6 & 19.4 & 6 & 18.8 \\
\hline $\begin{array}{l}\text { Provider-swab > Pap test }> \\
\text { Self-swab }\end{array}$ & 1 & 3.2 & 7 & 21.9 \\
\hline $\begin{array}{l}\text { Pap test > Self-swab > } \\
\text { Provider-swab }\end{array}$ & 0 & 0 & 1 & 3.2 \\
\hline $\begin{array}{l}\text { Pap test > Provider-swab > } \\
\text { Self-swab }\end{array}$ & 2 & 6.5 & 2 & 6.3 \\
\hline Summarized ranking & & & & \\
\hline $\begin{array}{l}\text { Preferred self-swab to Pap } \\
\text { test }\end{array}$ & 28 & 90.3 & 22 & 68.8 \\
\hline
\end{tabular}




\begin{tabular}{|l|c|c|c|c|}
\hline $\begin{array}{l}\text { Preferred self-swab to } \\
\text { provider-swab }\end{array}$ & 22 & 71.0 & 17 & 53.1 \\
\hline $\begin{array}{l}\text { Preferred provider-swab to } \\
\text { Pap test }\end{array}$ & 29 & 93.5 & 29 & 90.6 \\
\hline $\begin{array}{l}\text { Preferred either self- or } \\
\text { provider-swab to Pap test }\end{array}$ & 29 & 93.5 & 29 & 90.6 \\
\hline
\end{tabular}


Introduction

\section{Supplementary Appendix A: In-Depth Interview Guide}

First l'd like to start off by asking you a little bit about yourself and your health in general.

- Tell me a little bit about yourself.

- What do you do on a typical day?

- Who are the most important people in your life?

- How would you describe your gender identity?

- What has your transition process been like? Where would you describe yourself in the process of transition?

- How would you describe your sexual orientation and behavior? How has that changed or remained the same over the course of your transition?

- Where do you usually get your health care? How would you describe your relationship with this provider?

- How do you think your gender identity affects your interactions with health care providers?

- Do you think your race, ethnicity, class, or other aspects of your identity affect your interactions with health care providers - for better or for worse?

- When you need information about health issues or are making a decision about your health care, who or what do you usually consult for more information? (Probe: friends, health care providers, internet, community organizations, advocacy groups).

- How easy is it to access information about gynecological care in particular for trans men? What does this information look like?

What do trans men think about Pap tests?

We are conducting this study in order to better understand what trans men's experiences with Pap tests are like so that eventually we can make this experience better, so we want to hear about all the experiences you've had with Paps that you feel comfortable sharing - the good, the bad and the ugly.

- What do you know about Pap tests?

- Have you ever talked to your health care provider(s) about cervical cancer or Pap tests?

- How did this topic come up? Did someone introduce the topic?

- How comfortable did you feel asking your provider any questions you had?

- Have you ever had a Pap test?

For those who have had a Pap test before:

- Thinking back to your last Pap test, where did you get the test?

- How did you choose this location or provider?

- Was the person who performed the test your usual provider?

- What types of providers do you like to get your Pap test from? What about that provider made you decide to get a Pap test from them? 
- Was the test part of a regular annual physical exam or part of a visit for another reason, or did you go specifically to get a Pap?

- If for another reason, how did the topic of Paps come up during the visit?

- Did you expect to get a Pap test at that visit, or did you make the decision during the visit to get a Pap?

- What prompted you to get a Pap at that time?

- How did you receive the results of your Pap?

- What were the results of your last Pap test and what did you think about them?

- What steps did your provider recommend that you take?

- How did you proceed?

- Tell me more about your last Pap test. What was that experience like for you?

- What was your level of physical comfort or discomfort with the exam?

- What were your thoughts and emotions before, during, and after the exam?

- What was your interaction with the doctor like before, during, and after the exam?

- Have you had any negative experiences in the past that made you more anxious during the Pap? (Probe: trauma history, bad experiences with healthcare system, etc.)

- What would you have changed about this experience, if possible?

- Did you disclose or discuss your gender identity with the person who performed the test?

- Did you feel that having this person be aware of your gender identity affected your treatment, for better or for worse? How?

- Have you had a test come back as abnormal before? How did you follow up on those results? What was your experience with providers like during follow-up?

- What was your best experience with a Pap test like?

- What was your worst experience with a Pap test like? What were some strategies you used to cope (before/during/after)?

- How has the experience changed or remained the same over the course of transition?

- When you did get a Pap test, what motivated you to do so?

For participants who have never had a Pap test:

- What are some of the reasons you haven't had a Pap test in the past? (Probe: physical discomfort, emotional discomfort, treatment by provider, utility of the test, booking an appointment, provider gender, etc.)

- Have you discussed any of these concerns with your provider? How did that conversation go? 
- How often does your provider recommend to you to get a Pap test?

- Have you had any negative experiences in the past that make you less willing to do a Pap test or genital exams more generally? (Probe: trauma history, bad experiences with healthcare system, etc.)

For all participants:

- How does receiving gynecological care fit or not fit into your gender identity? Are there other medical procedures that bring up similar issues?

- Have you ever declined to get a Pap test when a doctor suggested you get one? What were your reasons for declining? (Probe: physical discomfort, emotional discomfort, treatment by provider, utility of the test, booking an appointment, provider gender, etc.)

- How useful do you think the Pap test is in preventing cervical cancer?

- How confident are you in the results of a Pap test?

- How often should trans men get tested?

- Is getting a Pap test more important for some people than others?

- What might be some reasons why trans men would be reluctant to get a Pap test?

- What are some reasons that would motivate trans men to have pap tests?

- What are some things that doctors can do to make trans men in particular feel comfortable during an exam?

- In your opinion, how could health care providers be more sensitive and attentive to issues of gender identity when providing gynecological care like Pap tests to people like you?

What do trans men think about HPV swabs? How would they compare to current screening programs in terms of patient acceptability?

- What do you know about the human papilloma virus and HPV testing?

I have with me the tools used in a Pap test, is it all right if I pull them out and show them to you? [Show a speculum/brush, and show a HPV swab and explain the test procedures]. The speculum is inserted into the vagina and widened so that the top end of the vagina, called the cervix, can be seen. The provider then takes this small brush to scrape some cells off the cervix to be tested. With the HPV swab, you or the provider would put the swab in the vagina and scrape the vaginal wall. Then you rinse off the swab in this tube and send it into the lab.

Clinicians here are thinking of offering trans men the option of doing a vaginal swab for HPV first, before doing a Pap. If the HPV results are normal, then they could skip the Pap test, and test for HPV again in 3 years. Those who took the HPV swab and had HPV detected would need to get a Pap test. Current guidelines don't include HPV swab and just recommend that everyone get Paps every 3 years.

- Compared to getting a Pap exam, how would you feel about getting an HPV swab?

- How would you feel about taking a swab yourself rather than having a doctor do it? 
- How confident are you in the results of a doctor-administered HPV swab? In a selfadministered swab? More or less confident than a Pap test?

- In what order would you prefer a Pap test, a doctor-administered swab, or a selfadministered swab?

- Assuming all three methods are equally accurate, in what order would you prefer them?

\section{Wrap Up}

- Is there anything else you'd like to share today?

- How was this interview for you? 
Eligibility Screen:

\section{Supplementary Appendix B: Online Survey}

1. How old are you?

2. Were you born with a cervix?

3. Do you currently identify as a trans man, FTM, on the FTM or transmasculine spectrum, nonbinary trans/genderqueer, etc.?

\section{Information Screen:}

The purpose of this research study is to learn more about experiences with, perceptions of, and barriers to cervical cancer screening, i.e. Pap tests or Pap smears, among people on the FTM spectrum. This will help us better understand what medical providers can do to make the process better for trans men.

Participation in this study is entirely voluntary. You don't have to answer every question, and there is space near the end to give us any additional information that you wish we had asked about. We will not collect your name or any directly identifiable information. Unfortunately, there is no monetary compensation for participating in this online survey.

The questions presented are taken from the full in-person interview. Please speak with as much detail as possible when you answer a question, since we won't be able to follow up with you for any additional information. Stories and long thoughts are welcome! We are looking for descriptions of your experiences and opinions, rather than brief factual answers.

When presenting our findings, we may quote what you have told us, but will not identify you (since we don't know who you are!). If you have any concerns about confidentiality or how we will use this information, please contact transprev@fenwayhealth.org or call 6179276412. Feel free to share the link to this interview to others on the FTM spectrum.

\section{Demographics:}

1. How do you identify in terms of race/ethnicity?

2. Describe your gender identity and/or transition process.

3. In the past 12 months, what has been the gender(s) of your sexual partner(s), if any?

4. How has your gender identity, race, class, sexuality, or other aspects of your identity affected your relationship with your health care provider(s), for better or for worse?

5. Approximately how many Paps have you had in the past? Please include in this number any times you had your doctor try to give you a Pap, but you were unable to complete the Pap.

\section{For all respondents:}

Some open-ended questions follow. Please feel free to respond to those that are most important to your personal experience.

1. Do you think your race, ethnicity, class, gender, or other aspects of your identity affect your interactions with health care providers - for better or for worse? How? 
2. What do you know about Pap tests (what is the purpose of the test, what happens during the test, etc)? Where did you get this information? Where can you find specific information available about Paps for people on the FTM spectrum?

3. What motivates you to have Pap tests?

4. What makes you reluctant to have Pap tests?

5. How do Pap tests fit - or not fit - into your gender identity? What gender issues do they bring up for you, if any?

6. In your opinion, how can health care providers be more sensitive to issues of gender identity when providing gynecological care like Pap tests to people like you?

7. If we were to design an outreach campaign (brochures, website, short videos, etc.) to give information about Paps specific to people on the FTM spectrum, what type of information would you include to encourage people to come in for Paps? What type of images or language would you include (or avoid)? Feel free to share what would motivate you personally to come in for Paps, as well as what you think would resonate with the broader community.

If you have had or tried to have a Pap test before, please consider the following questions. If you have never had a Pap test before, please skip to the next section.

1. What have your experiences with Pap tests been like for you? (You might include your level of physical comfort, thoughts or emotions during the exam, your interactions with the doctor, etc.)

2. Did you disclose or discuss your gender identity with the person who performed your last Pap test? Did this affect your treatment-- for better or for worse? How?

3. What was your best experience with a Pap test like? What did you or your provider do to make yourself more comfortable?

4. What was your worst experience with a Pap test like? What were some strategies you used to cope (before/during/after)? How helpful were these strategies?

5. What advice would you give to medical providers about how to make the exam better for patients on the FTM spectrum?

6. Has your experience with Paps or views of Paps changed at all over the course of your social or medical transition? Please explain.

7. Please feel free to share below anything about Paps that you want to talk about, even if we didn't ask about it specifically:

If you have never had a Pap test done, please consider the questions below.

1. What are some of the reasons you haven't had a Pap test in the past?

2. Have you had any negative experiences in the past (whether with the medical system or in life more broadly) that make you less willing to do a Pap test or genital exams more generally?

3. Have you discussed any of these concerns with your provider? How did that conversation go?

4. How often does your provider recommend for you to get a Pap test? If they did suggest that you get a Pap test, what made you decline one at the time?

5. Please feel free to share below anything about Paps that you want to talk about, even if we didn't ask about it specifically:

Even if you've never had a Pap test, please consider the following information and questions: 
Clinicians at Fenway Health are thinking of offering patients the option of doing a swab for human papillomavirus (HPV) first, before doing a Pap. If HPV is not detected, then they could skip the Pap test. Those who took the HPV swab and had HPV detected would need to get a Pap test. The idea is that HPV is the cause of almost all cervical cancers, so if you do not have HPV, you are unlikely to be at risk of cervical cancer. Current guidelines don't include HPV swab and just recommend that everyone get Paps every 3 years.

Below is a description of the Pap test and the HPV test, and pictures of the tools doctors use for each one. After explaining the tests, we will ask some questions about which test you might prefer and why.

Pap test: The speculum (tool on the left) is inserted into the vagina and widened slightly (as shown) so that the doctor can see the cervix clearly, and then a plastic brush, broom, or spatula (tools on the right) is inserted to brush cells from the cervix. The brush is then removed and the cells are rinsed off in a vial of liquid and sent to a lab for analysis.

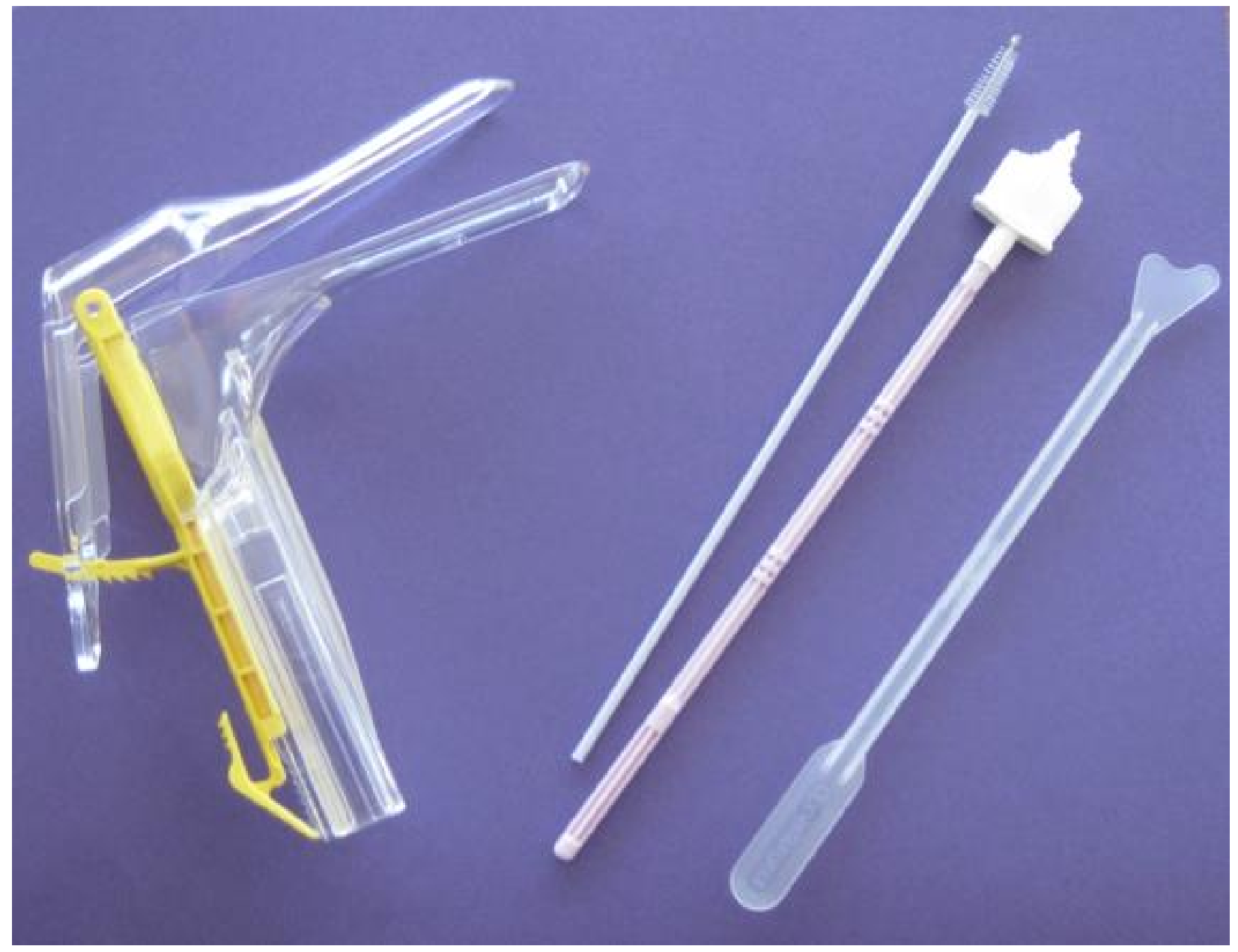

$\underline{H P V \text { test }}$ 
This is a picture of the swabs (looks similar to a large Q-tip) used for the HPV test. A speculum is not required, the provider inserts the swab directly, swabs around the walls of the canal a few times, and then removes the swab and places it in a container to send to the lab. Sometimes the second swab is used as well to get more of a sample.

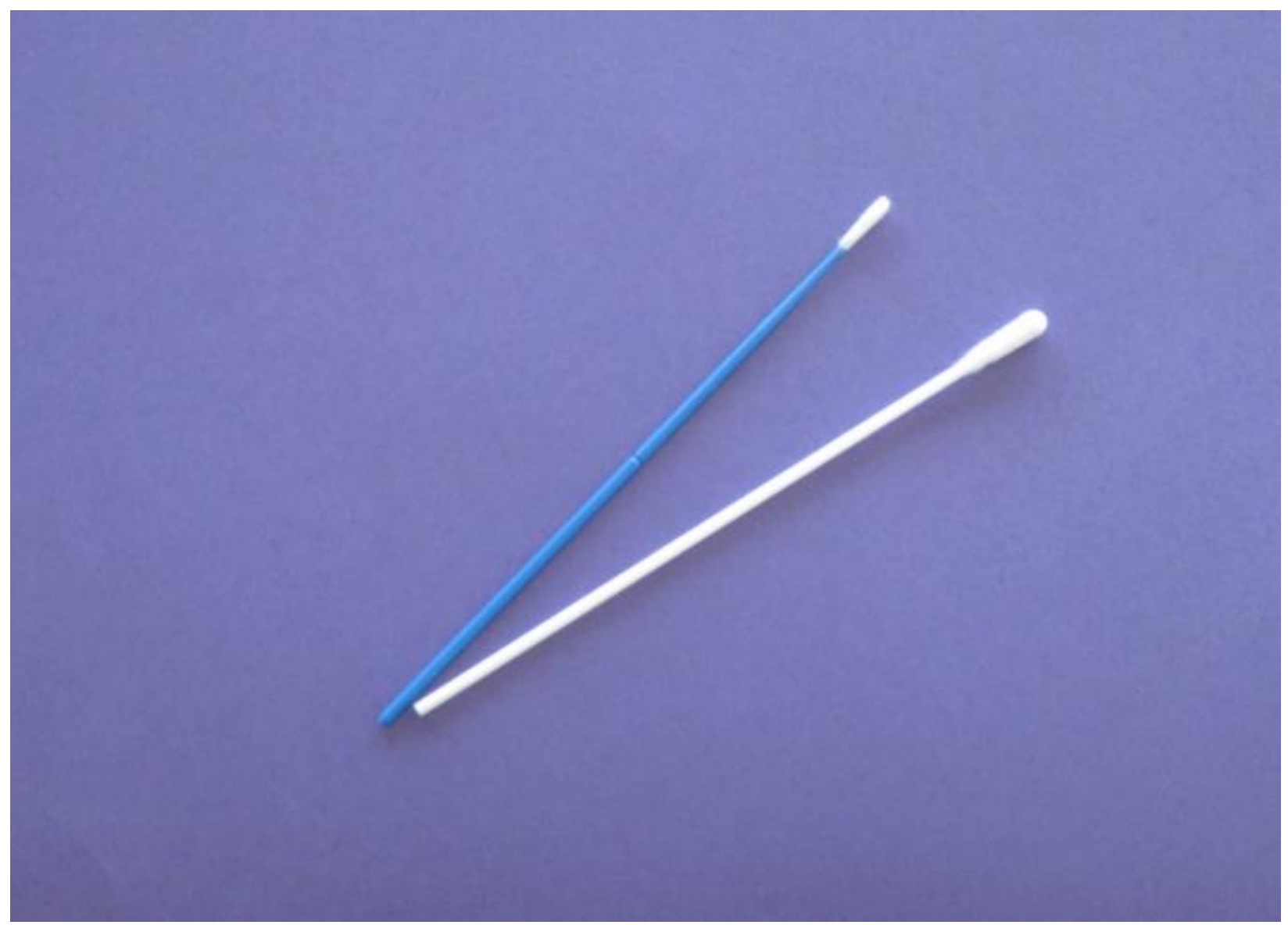

1. Compared to getting a Pap exam, how would you feel about having a provider perform an HPV test? What, specifically, would be better or worse about each test (you might speak to physical comfort, mental/emotional comfort, your confidence in the test, etc)?

2. There may be an option to administer the HPV swab yourself (a self-swab) at your provider's office rather than having your provider do it. Your provider could leave the room while you inserted the swab yourself, or they could remain on hand for questions as you preferred. How would you feel about taking a HPV swab yourself rather than having a provider do it? 3. In what order would you prefer a Pap test, a provider-administered swab, or a selfadministered swab? Why?

4. We would like to have a study at Fenway to compare a self-administered HPV swab, a provider-administered HPV swab, and a Pap test to test whether they are equally accurate. If shown to be effective, patients could have the option of undergoing the HPV test instead of the Pap to screen for cervical cancer. The HPV test has been shown in research studies to be an effective screening method for cervical cancer for non-transgender women, but no studies have yet been conducted with people on the FTM spectrum. 
Participants in such a study would have to undergo a self-administered HPV test, a provideradministered HPV test, a Pap, and a colposcopy. A colposcopy is like a Pap in that it involves a speculum, but is slightly more involved in that the doctor uses a low-powered microscope to look more directly at the cervix, and takes a small biopsy (tissue sample of about 3 millimeters) to look directly at the tissue. The microscope remains outside the body. The biopsy feels like a pinch or cramp. Participants would then return 12 months later and undergo a selfadministered HPV swab, a doctor-administered HPV swab, and a Pap (but not a second colposcopy).

[Participants were able to view a picture of a patient in a gown and stirrups here; this picture was removed from the published appendix out of sensitivity for sharing patient photos]

1. How valuable would the results of such a study be to the trans community? How interested would you be in participating in such a study? What concerns would you have? What would motivate you to sign up? How much monetary incentive do you think would be fair? 


\section{References}

1. Bosch FX, Manos MM, Muñoz N, Sherman M, Jansen AM, Peto J, et al. Prevalence of human papillomavirus in cervical cancer: a worldwide perspective. International biological study on cervical cancer (IBSCC) Study Group. J Natl Cancer Inst. 1995 Jun 7;87(11):796-802.

2. Walboomers JM, Jacobs MV, Manos MM, Bosch FX, Kummer JA, Shah KV, et al. Human papillomavirus is a necessary cause of invasive cervical cancer worldwide. J Pathol. 1999 Sep;189(1):12-9.

3. Reisner SL, Deutsch MB, Peitzmeier SM, White Hughto JM, Cavanaugh T, Pardee DJ, et al. Comparing self- and provider-collected swabbing for HPV DNA testing in female-to-male transgender adult patients: a mixed-methods biobehavioral study protocol. BMC Infect Dis. 2017 Jun 23;17(1):444.

4. Sexually transmitted diseases treatment guideline [Internet]. Center for Disease Control and Prevention (CDC). [cited 2018 Jan 9]. Available from: https://www.cdc.gov/std/treatment/2010/default.htm

5. Satterwhite CL, Torrone E, Meites E, Dunne EF, Mahajan R, Ocfemia MCB, et al. Sexually transmitted infections among US women and men: prevalence and incidence estimates, 2008. Sex Transm Dis. 2013 Mar;40(3):187-93.

6. McQuillan G, Kruszon-Moran D, Markowitz LE, Unger ER, Paulose-Ram R. Prevalence of HPV in Adults Aged 18-69: United States, 2011-2014 [Internet]. Centers for Disease Control and Prevention, National Center for Health Statistics; 2017 Apr [cited 2018 Jan 9]. Report No.: NCHS Data Brief N. 280. Available from: https://www.cdc.gov/nchs/products/databriefs/db280.htm

7. UCSF Center of Excellence for Transgender Health. Guidelines for the Primary and GenderAffirming Care of Transgender and Gender Nonbinary People: Terminology and definitions [Internet]. [cited 2017 Mar 29]. Available from:

http://transhealth.ucsf.edu/trans?page=guidelines-terminology

8. Flores AR, Herman JL, Gates GJ, Brown TNT. How Many Adults Identify as Transgender in the United States? [Internet]. Los Angeles, CA: The Williams Institute; 2016 Jun [cited 2017 Jul 17]. Available from: http://williamsinstitute.law.ucla.edu/wp-content/uploads/HowMany-Adults-Identify-as-Transgender-in-the-United-States.pdf

9. Kaufman R. Introduction to transgender identity and health. In: Makadon H, Mayer K, Potter J, Goldhammer H, editors. The Fenway Guide to Lesbian, Gay, Bisexual, and Transgender Health. Second Edition. American College of Physicians; 2015.

10. Bauer GR, Travers R, Scanlon K, Coleman TA. High heterogeneity of HIV-related sexual risk among transgender people in Ontario, Canada: a province-wide respondent-driven sampling survey. BMC Public Health. 2012 Apr 20;12:292. 
11. Peitzmeier SM, Reisner SL, Harigopal P, Potter J. Female-to-male patients have high prevalence of unsatisfactory Paps compared to non-transgender females: implications for cervical cancer screening. J Gen Intern Med. 2014 May;29(5):778-84.

12. Health Care for Transgender Individuals [Internet]. American College of Obstetricians and Gynecologists; 2011 Dec [cited 2016 Oct 18]. Available from:

http://www.acog.org/Resources-And-Publications/Committee-Opinions/Committee-onHealth-Care-for-Underserved-Women/Health-Care-for-Transgender-Individuals

13. Cervical Cancer Screening [Internet]. American College of Obstetricians and Gynecologists; 2016 Feb [cited 2016 Oct 18]. Available from: http://www.acog.org/Patients/FAQs/Cervical-Cancer-Screening.

14. Committee on Practice Bulletins-Gynecology. Practice Bulletin No. 168: Cervical Cancer Screening and Prevention. Obstet Gynecol. 2016;128(4):e111-130.

15. Saslow D, Solomon D, Lawson HW, Killackey M, Kulasingam S, Cain J, et al. American Cancer Society, American Society for Colposcopy and Cervical Pathology, and American Society for Clinical Pathology Screening guidelines for the Prevention and early Detection of Cervical Cancer. Am J Clin Pathol. 2012;137(4):516-42.

16. Moyer VA, U.S. Preventive Services Task Force. Screening for cervical cancer: U.S. Preventive Services Task Force recommendation statement. Ann Intern Med. 2012 Jun 19;156(12):880-91, W312.

17. Feldman S, Crum C. Cervical cancer screening tests: Techniques for cervical cytology and human papillomavirus testing. UpToDate. http://www.uptodate.com.

18. Feldman S, Goodman A, Peipert JF. Screening for cervical cancer [Internet]. UpToDate. [cited 2018 Jan 9]. Available from: http://www.uptodate.com

19. Updated Consensus Guidelines on the Management of Women with Abnormal Cervical Cancer Screening Tests and Cancer Precursors [Internet]. The American Society for Colposcopy and Cervical Pathology (ASCCP). 2013 [cited 2017 Mar 24]. Available from: http://www.asccp.org/asccp-guidelines

20. Wilt TJ, Harris RP, Qaseem A, High Value Care Task Force of the American College of Physicians. Screening for cancer: advice for high-value care from the American College of Physicians. Ann Intern Med. 2015 May 19;162(10):718-25.

21. FDA approves first HPV test for use with SurePath Preservative Fluid [Internet]. US Food \& Drug Administration. 2016 [cited 2018 Jan 9]. Available from: https://www.fda.gov/NewsEvents/Newsroom/PressAnnouncements/ucm510251.htm 
22. Wright TC, Stoler MH, Behrens CM, Sharma A, Zhang G, Wright TL. Primary cervical cancer screening with human papillomavirus: end of study results from the ATHENA study using HPV as the first-line screening test. Gynecol Oncol. 2015 Feb;136(2):189-97.

23. Feldman J. Preventive care of the transgendered patient: an evidence-based approach. In: Ettner R, Monstrey S, Eyler AE, editors. Principles of Transgender Medicine and Surgery. Haworth Press; 2007. p. 33-72.

24. Kenagy GP. Transgender health: findings from two needs assessment studies in Philadelphia. Health Soc Work. 2005 Feb;30(1):19-26.

25. O'Hanlan KA, Dibble SL, Young-Spint M. Total laparoscopic hysterectomy for female-to-male transsexuals. Obstet Gynecol. 2007 Nov;110(5):1096-101.

26. van Trotsenburg MAA. Gynecological Aspects of Transgender Healthcare. Int J Transgenderism. 2009 Nov 30;11(4):238-46.

27. Potter J, Peitzmeier SM, Bernstein I, Reisner SL, Alizaga NM, Agénor M, et al. Cervical Cancer Screening for Patients on the Female-to-Male Spectrum: a Narrative Review and Guide for Clinicians. J Gen Intern Med. 2015 Dec;30(12):1857-64.

28. Rachlin K, Green J, Lombardi E. Utilization of health care among female-to-male transgender individuals in the United States. J Homosex. 2008;54(3):243-58.

29. Instructions Regarding Processing Claims Rejecting for Gender/Procedure Conflict [Internet]. Centers for Medicare and Medicaid Services; 2009 Dec [cited 2016 Oct 18]. Available from: https://www.cms.gov/Outreach-and-Education/Medicare-LearningNetwork-MLN/MLNMattersArticles/Downloads/MM6638.pdf

30. Denny L. Screening for cervical cancer in resource-limited settings [Internet]. UpToDate. 2016 [cited 2017 Jan 9]. Available from: http://www.uptodate.com

31. Nobbenhuis M a. E, Helmerhorst TJM, van den Brule AJC, Rozendaal L, Jaspars LH, Voorhorst FJ, et al. Primary screening for high risk HPV by home obtained cervicovaginal lavage is an alternative screening tool for unscreened women. J Clin Pathol. 2002 Jun;55(6):435-9.

32. Nelson EJ, Maynard BR, Loux T, Fatla J, Gordon R, Arnold LD. The acceptability of selfsampled screening for HPV DNA: a systematic review and meta-analysis. Sex Transm Infect. 2017 Feb;93(1):56-61.

33. Virtanen A, Nieminen P, Niironen M, Luostarinen T, Anttila A. Self-sampling experiences among non-attendees to cervical screening. Gynecol Oncol. 2014 Dec;135(3):487-94. 
34. Fairley CK, Chen S, Tabrizi SN, Quinn MA, McNeil JJ, Garland SM. Tampons: a novel patientadministered method for the assessment of genital human papillomavirus infection. J Infect Dis. 1992 Jun;165(6):1103-6.

35. Bosgraaf RP, Ketelaars PJW, Verhoef VMJ, Massuger LFAG, Meijer CJLM, Melchers WJG, et al. Reasons for non-attendance to cervical screening and preferences for HPV selfsampling in Dutch women. Prev Med. 2014 Jul;64:108-13.

36. Dzuba IG, Díaz EY, Allen B, Leonard YF, Lazcano Ponce EC, Shah KV, et al. The acceptability of self-collected samples for HPV testing vs. the pap test as alternatives in cervical cancer screening. J Womens Health Gend Based Med. 2002 Apr;11(3):265-75.

37. Gök M, Heideman DAM, van Kemenade FJ, Berkhof J, Rozendaal L, Spruyt JWM, et al. HPV testing on self collected cervicovaginal lavage specimens as screening method for women who do not attend cervical screening: cohort study. BMJ. 2010 Mar 11;340:c1040.

38. Wong ELY, Cheung AWL, Huang F, Chor JSY. Can Human Papillomavirus DNA Self-sampling be an Acceptable and Reliable Option for Cervical Cancer Screening in Female Sex Workers? Cancer Nurs. 2017 Jan 20;

39. Kobetz E, Seay J, Amofah A, Pierre L, Bispo JB, Trevil D, et al. Mailed HPV self-sampling for cervical cancer screening among underserved minority women: study protocol for a randomized controlled trial. Trials. 2017 Jan 13;18(1):19.

40. Snijders PJF, Verhoef VMJ, Arbyn M, Ogilvie G, Minozzi S, Banzi R, et al. High-risk HPV testing on self-sampled versus clinician-collected specimens: a review on the clinical accuracy and impact on population attendance in cervical cancer screening. Int J Cancer. 2013 May 15;132(10):2223-36.

41. Zhao F-H, Lewkowitz AK, Chen F, Lin MJ, Hu S-Y, Zhang X, et al. Pooled analysis of a selfsampling HPV DNA Test as a cervical cancer primary screening method. J Natl Cancer Inst. 2012 Feb 8;104(3):178-88.

42. Holanda F, Castelo A, Veras TMCW, de Almeida FML, Lins MZ, Dores GB. Primary screening for cervical cancer through self sampling. Int J Gynaecol Obstet Off Organ Int Fed Gynaecol Obstet. 2006 Nov;95(2):179-84.

43. Racey CS, Withrow DR, Gesink D. Self-collected HPV testing improves participation in cervical cancer screening: a systematic review and meta-analysis. Can J Public Health Rev Can Sante Publique. 2013 Feb 11;104(2):e159-166.

44. Haguenoer K, Sengchanh S, Gaudy-Graffin C, Boyard J, Fontenay R, Marret H, et al. Vaginal self-sampling is a cost-effective way to increase participation in a cervical cancer screening programme: a randomised trial. Br J Cancer. 2014 Nov 25;111(11):2187-96. 
45. Giorgi Rossi P, Marsili LM, Camilloni L, lossa A, Lattanzi A, Sani C, et al. The effect of selfsampled HPV testing on participation to cervical cancer screening in Italy: a randomised controlled trial (ISRCTN96071600). Br J Cancer. 2011 Jan 18;104(2):248-54.

46. Mayer K, Appelbaum J, Rogers T, Lo W, Bradford J, Boswell S. The evolution of the Fenway Community Health model. Am J Public Health. 2001 Jun;91(6):892-4.

47. Charmaz K. Constructing Grounded Theory: A Practical Guide through Qualitative Analysis. First Edition. Sage Publications, Inc.; 2006. 208 p.

48. Braun V, Clarke V. Using thematic analysis in psychology. Qual Res Psychol. 2006;3(2):77101.

49. Robert Wood Johnson Foundation. Qualitative Research Guidelines Project | Triangulation [Internet]. [cited 2017 Mar 12]. Available from: http://www.qualres.org/HomeTria3692.html

50. Shadish WR, Cook TD, Campbell DT. Experimental and Quasi-Experimental Designs for Generalized Causal Inference. 2 edition. Boston: Cengage Learning; 2001. 656 p.

51. Shadish WR, Baldwin SA. Meta-analysis of MFT interventions. J Marital Fam Ther. 2003 Oct;29(4):547-70.

52. Patton M. Qualitative Evaluation and Research Methods. 3rd Edition. Thousand Oaks, California: Sage Publications, Inc.; 2002.

53. Morse J. Designing funded qualitative research. In: Handbook for qualitative research. Thousand Oaks, California: Sage; 1994. p. 220-35.

54. Creswell JW. Qualitative Inquiry and Research Design: Choosing Among Five Approaches. Third Edition. Sage Publications, Inc.; 2012. 472 p.

55. Palinkas LA, Horwitz SM, Green CA, Wisdom JP, Duan N, Hoagwood K. Purposeful sampling for qualitative data collection and analysis in mixed method implementation research. Adm Policy Ment Health. 2015 Sep;42(5):533-44.

56. US Preventive Services Task Force. Cervical Cancer: Screening [Internet]. [cited 2017 Mar 29]. Available from:

https://www.uspreventiveservicestaskforce.org/Page/Document/UpdateSummaryFinal/ce rvical-cancer-screening

57. Corbin J, Strauss A. Basics of Qualitative Research: Techniques and Procedures for Developing Grounded Theory. 3rd Edition. Thousand Oaks, California: Sage Publications, Inc.; 2008. 
58. Lincoln YS \$\$Qincoln. Naturalistic inquiry. Beverly Hills, Calif.: Sage Publications; 1985. 416 p.

59. Peitzmeier SM, Khullar K, Reisner SL, Potter J. Pap test use is lower among female-to-male patients than non-transgender women. Am J Prev Med. 2014 Dec;47(6):808-12.

60. Grant J, Mottet L, Tanis J, Harrison J, Herman J, Keisling M. Injustice at every turn: a report of the national transgender discrimination survey [Internet]. National Center for Transgender Equality \& National Gay and Lesbian Taskforce; 2011 [cited 2016 Oct 18]. Available from: http://endtransdiscrimination.org/PDFs/NTDS_Report.pdf

61. Crosby RA, Hagensee ME, Vanderpool R, Nelson N, Parrish A, Collins T, et al. CommunityBased Screening for Cervical Cancer: A Feasibility Study of Rural Appalachian Women. Sex Transm Dis. 2015 Nov;42(11):607-11.

62. Sultana F, Mullins R, English DR, Simpson JA, Drennan KT, Heley S, et al. Women's experience with home-based self-sampling for human papillomavirus testing. BMC Cancer. 2015 Nov 4;15:849.

63. Szarewski A, Cadman L, Ashdown-Barr L, Waller J. Exploring the acceptability of two selfsampling devices for human papillomavirus testing in the cervical screening context: a qualitative study of Muslim women in London. J Med Screen. 2009;16(4):193-8.

64. Baldassarre M, Giannone FA, Foschini MP, Battaglia C, Busacchi P, Venturoli S, et al. Effects of long-term high dose testosterone administration on vaginal epithelium structure and estrogen receptor- $\alpha$ and $-\beta$ expression of young women. Int J Impot Res. 2013 Sep;25(5):172-7.

65. Thomas C. Wright J, Denny L, Kuhn L, Pollack A, Lorincz A. HPV DNA Testing of Self-collected Vaginal Samples Compared With Cytologic Screening to Detect Cervical Cancer. JAMA. 2000 Jan 5;283(1):81-6.

66. Fokom-Domgue J, Combescure C, Fokom-Defo V, Tebeu PM, Vassilakos P, Kengne AP, et al. Performance of alternative strategies for primary cervical cancer screening in sub-Saharan Africa: systematic review and meta-analysis of diagnostic test accuracy studies. BMJ. 2015 Jul 3;351:h3084.

67. Burns RB, Potter JE, Ricciotti HA, Reynolds EE. Screening Pelvic Examinations in Adult Women: Grand Rounds Discussion From the Beth Israel Deaconess Medical Center. Ann Intern Med. 2015 Oct 6;163(7):537-47.

68. Roche Molecular Systems, Inc. Medical Devices Advisory Committee Panel Meeting Sponsor Executive Summary: $\operatorname{cobas}^{\circledR}$ HPV Test [Internet]. 2014 Jan [cited 2017 Mar 29]. Available from:

https://www.fda.gov/downloads/advisorycommittees/committeesmeetingmaterials/medi caldevices/medicaldevicesadvisorycommittee/microbiologydevicespanel/ucm388565.pdf 
69. Huh WK, Ault KA, Chelmow D, Davey DD, Goulart RA, Garcia FAR, et al. Use of primary highrisk human papillomavirus testing for cervical cancer screening: interim clinical guidance. Gynecol Oncol. 2015 Feb;136(2):178-82. 